\title{
ESTUDIO MORFOLÓGICO DE LOS CANALES RADICULARES DEL PRIMER PREMOLAR SUPERIOR, UTILIZANDO RADIOGRAFÍA PERIAPICAL Y TOMOGRAFÍA DE HAZ CÓNICO, EN EL CENTRO RADIOLÓGICO DENTAL-MAXILOFACIAL, CUENCA 2015
}

\author{
COBOS-PARRA DIEGO* \\ MOSCOSCO-ABAD MARÍA**
}

\author{
Recibido: 27/11/2015 \\ Aceptado: 09/12/2015
}

\section{RESUMEN}

La CBCT (cone beam computed tomography), es un gran avance en el diagnóstico por imágenes. Se basa en la reconstrucción de imágenes en $3 \mathrm{D}$ para un diagnóstico más acertado. El presente estudio tiene por objeto estudiar la morfología de los canales radiculares del primer premolar superior, utilizando radiografía periapical y tomografía de haz cónico.

El tipo de estudio es in vitro, descriptivo y transversal, la muestra es por conveniencia, puesto que no se dispuso de una población específica para guia, por lo que se seleccionaron 50 dientes (Primeros Premolares Superiores), extraídos por motivo ortodóntico. Las imágenes obtenidas mediante radiografías intra orales revelan una información en dos dimensiones, lo que nos limita en el diagnóstico. En determinadas situaciones la visualización en tres dimensiones de un problema endodóntico es necesaria. El resultado del presente estudio denota que radiográficamente se obtienen datos acertados sobre la morfología de las piezas que presentaban un solo conducto o dos raíces separadas, siendo más efectivo el uso de la tomografía para la descripción de piezas con un sistema de conductos más complejo.

Palabras clave: morfología interna, CBTC, radiografía periapical, primer premolar superior.

\section{ABSTRACT}

The CBCT (cone beam computed tomography) is a breakthrough in imaging. It is based on the reconstruction of $3 D$ images for a more accurate diagnosis. This study aims to study the morphology of the root canal of the maxillary first premolar, using periapical radiography and cone beam tomography.

The type of study is in vitro, descriptive and cross-sectional sample is for convenience, because we do not have a specific population to guide us, so we selected 50 teeth (first premolars Institutions), extracted for orthodontic reasons. The images obtained by intra oral radiographs reveal information in two dimensions, limiting us to the diagnosis. In certain situations where the three-dimensional visualization of an endodontic problem is necessary. The result of this study indicates that accurate data radiographically morphology parts duct presenting one or two separate roots are obtained, being the most effective use of tomography parts for describing a more complex system of ducts.

Keywords: Internal morphology, CBTC, periapical, first upper premolar.

\section{INTRODUCCIÓN}

El fracaso en Endodoncia se ha relacionado con diferentes factores: obturación incompleta del sistema de conductos radiculares, filtración coronal y fallos por parte del operador en reconocer la presencia de conductos y sus ramificaciones. Esto subraya la importancia de incrementar el conocimiento de la compleja anatomía de los conductos radiculares, lo que constituye uno de los objetivos principales de la Endodoncia. En estudios anteriores, han sido descritas diversas variaciones en la anatomía del sistema de conductos radiculares.

Hasta la fecha muchas han sido las técnicas y estudios que han surgido para un mayor y mejor conocimiento de la anatomía externa e interna. Las imágenes obtenidas mediante técnicas radiográficas presentan ciertas limitaciones derivadas de su bidimensionalidad, lo que permite una interpretación subjetiva de las mismas. Pero con el desarrollo de técnicas como la tomografía computariza de haz cónico, en inglés "Cone Beam Computed Tomography" (CBCT) con el objetivo de obtener un escaneo tridimensional del esqueleto maxilofacial, a esto se suma el beneficio de obtener imágenes sin superposición, sin distorsión y con una resolución sub-milimétrica que se traduce en imágenes de alta calidad diagnóstica mejorando la calidad del tratamiento.

** Docente Especialista en Endodoncia, Universidad Católica de Cuenca.Ecuador 


\section{MATERIALES Y MÉTODOS}

Imágenes Tomográficas. Las imágenes 3D están constituidas por vóxels en lugar de pixels que son los que determinan las imágenes digitales 2D. El tamaño de cada vóxel depende de su altura, ancho y grosor o profundidad y es el elemento más pequeño del volumen de la figura radiográfica 3D. En la CBCT, los vóxeles son isotrópicos, (iguales en longitud, altura y profundidad), lo que permite unas mediciones geométricamente precisas de los datos estudiados en cualquier plano. Aunque la radiografía periapical es más práctica para endodoncia, el CBCT permite identificar con exactitud el número y forma de los conductos radiculares, y sus curvaturas $^{1,17}$. Matherne y col. llevaron a cabo una investigación para comparar un sistema de radiografías digitales fotoestimulables de placas de fósforo con CBCT para detectar el número de conductos radiculares en 72 piezas extraídas. Se comprobó que con la radiografía digital los endodoncistas no lograron identificar al menos uno de los conductos en el $40 \%$ de los casos. ${ }^{2}$

Sistema de conductos radiculares: El sistema de conductos radiculares está dividido en dos porciones la cámara pulpar, localizada en la corona anatómica del diente y el conducto (o conductos) pulpar o radicular, localizado en la raíz anatómica. Entre las demás características morfológicas se incluyen: cuernos pulpares, conductos accesorios, laterales y de furcación; orificios de los conductos; delta ápices, y forámenes apicales ${ }^{3}$. Casi todos los conductos radiculares son curvos, particularmente en dirección VL, esas curvas pueden plantear problemas durante los procedimientos de conformación y limpieza debido a que no se aprecian en una radiografía vestibular estándar. Son necesarias proyecciones anguladas para determinar su presencia, dirección e intensidad. ${ }^{3}$

El sistema de conductos pulpares es complejo y los conductos se pueden ramificar, dividir y volver a juntar. Vertucci utilizando 400 primeros premolares superiores diafanizados, pudo realizar una clasificación del sistema de conductos, identificando ocho configuraciones del espacio pulpar que se describirá más adelante. Determinando que existe raíz única en el 39,5\% de los casos, 56,5\% doble raíz y un $4 \%$ de los casos encontró tres raíces ${ }^{4,15}$. Los conductos se pueden clasificar según su tipo, del 1 al 8 (Vertucci et al 1979). (Fig. 1). 4, 15

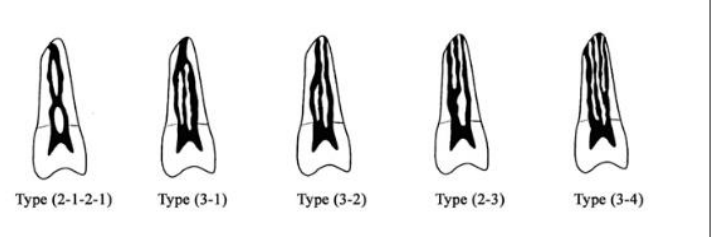

Fig. 1: Tipos de conductos que podemos encontrar en primer premolar superior. Vertucci et al 1979.

Otro conjunto de variantes fue observado por primera vez en sujetos birmanos; ese estudio revelo siete configuraciones de conductos radiculares adicionales descritos por Gulavibala. (Fig. 2) ${ }^{5}$.

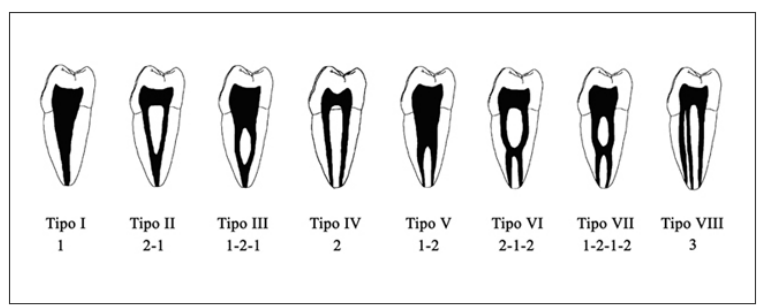

Fig. 2. Clasificación adicional de Gulabivala 2002.

Foramen Apical (FA): El foramen, es el orificio apical de tamaño considerable, que puede suponer como la terminación del conducto principal. Se confunde con frecuencia el foramen con el ápice, o con el vértice radicular. Diversos estudios han demostrado que el FA coincide con el vértice del ápice radicular entre el 17\% a $46 \%$ de los casos $^{6}$

De igual manera, para Kuttler, el cono cementario, muy pocas veces sigue el eje axial del conducto radicular, por el contrario, comúnmente se desvía lateralmente en la mayoría de los casos, llegando, a veces, a salir a $3 \mathrm{~mm}$ del vértice apical y, con mayor frecuencia, hacia distal. Esto representa un problema para los endodoncistas, ya que este fenómeno se detecta en las radiografías sólo cuando el foramen termina en la cara mesial o distal de la raíz, pero cuando termina por vestibular o lingual no es posible reconocerlo radiográficamente; entonces la sobre instrumentación del conducto debe ser frecuente e involuntaria ${ }^{6}$. 
Cada uno de los dientes de la muestra estuvo sometido a un proceso de limpieza mediante ultrasonido para la remoción de cálculo y restos de tejido periodontal. Posteriormente las piezas seleccionadas fueron sometidas a un estudio tomográfico ${ }^{14}$.

La unidad diagnóstica empleada fue Newton VGI Flex; ayudándonos del software NNT Viewer versión 2.21; además para realizar la toma de la tomografía se utilizó una caja con medidas específicas para el equipo utilizado, que en su parte central inferior presentaba un cuadrado con malla milimetrada mediante el cual pudimos centrar en el equipo para colocar las coordenadas con el plano sagital y medio, para reconstruir fielmente las estructuras dentales.

El análisis tomográfico nos permite realizar cortes seriados del sistema de conductos cada 0,3 mm, obteniendo una media de 70 cortes por diente, dependiendo, claro está, de la longitud de la muestra. Como podemos observar en la imagen, el software permite a su vez realizar cortes paralelos o perpendiculares al eje axial, a cualquier altura del conducto. Pudiendo conocer, fielmente el diámetro del canal a cualquier nivel: tercio coronal, tercio medio o tercio apical. (Fig. 3) ${ }^{7}$.

Posterior a esto tomamos radiografías periapicales de las mismas piezas que fueron sometidas a la tomografía axial computarizada de haz cónico dicha radiografía fue tomada con las piezas en las mismas condiciones en las que se presentaron para realizar la figura tomográfica, sin variar posición u orden alguna de las piezas estudiadas. El equipo usado para la toma de las radiografías digitales fue un equipo Digora Digital Optime de la marca Soderex con un software tomográfico Scanora. (Fig. 4.)

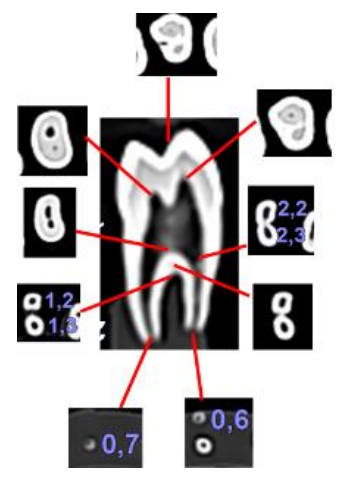

Fig. 3. Tomografía de Haz Cónico. Fuente. Propia

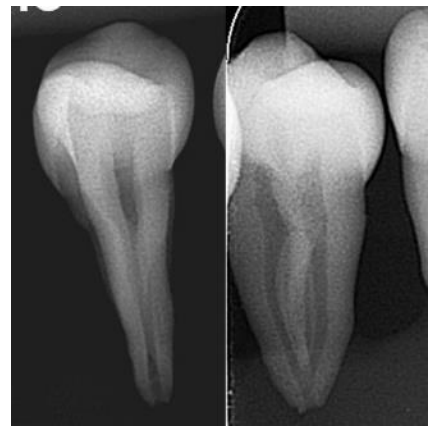

Fig. 4. Radiografía periapical Fuente. Propia

TÉCNICA DE LA DIAFANIZACIÓN. La diafanización es un proceso mediante el cual una muestra se

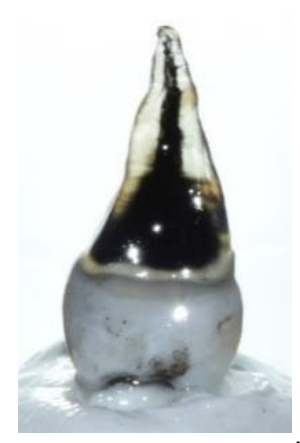

Fig. 5. Pieza Fuente. Propia transparenta, mediante técnicas que igualan los índices de refracción de la luz del interior del órgano con el medio que lo contiene. Dicho de otra manera la diafanización dental es una técnica de desmineralización que se utiliza para transparentar dientes in vitro por medio de sustancias químicas que actúan sobre los componentes orgánicos e inorgánicos del diente, proceso con el cual podremos observar al final la anatomía radicular de una manera tridimensional5. (Fig. 5).

El precedente actual de diafanización en endodoncia es el método descrito por Robertson a principios de los 80 en el cual se desarrolla el protocolo siguiente:

Para el desarrollo de la técnica, los dientes se lavaron con agua corriente y se conservaron en solución fisiológica hasta su preparación, posteriormente se limpiaron y se les retiró restos de tejido para proseguir con el resto del procedimiento 6,23 .

1. Se guardaron individualmente en frascos de vidrio con tapa y se sumergieron en hipoclorito de sodio al $10 \%$ durante 20 minutos. (Fig. 6) 6,23

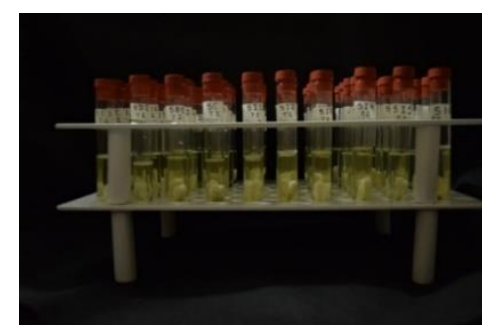

Fig. 6. Fotografía de las piezas dentales estudiadas sumergidas en Hipoclorito de Sodio al 10\%. Fuente. Propia. 
2. Se les realizó el acceso al sistema de conductos radiculares con pieza de mano de alta velocidad, fresa redonda y fresa Endo-Z, localizando la entrada de los conductos en el piso pulpar para inyectarles tinta de color azul con una jeringa. ${ }^{6,23}$

3. Se dejó secar la tinta por 24 horas.

4. Pasadas las 24 horas se cubrió la corona anatómica con cera rosada, sellándola con una espátula caliente a nivel cervical para evitar que se escurra la tinta; posteriormente se les colocó en ácido nítrico al 5\%, cubriéndose el doble del volumen de los dientes y se dejó en reposo por 48 horas. Se cambió el ácido nítrico al $5 \%$ a las 24 horas y se lavaron con agua corriente por tres minutos, envueltos en una gasa. (Fig. 7.) 6,23

4. Después se dejaron secar a temperatura ambiente por cuatro horas y se colocaron en frascos nuevos conteniendo alcohol de $96^{\circ}$ al $80 \%$ por 12 horas, posteriormente alcohol al $90 \%$ por tres horas y nuevamente alcohol de $96^{\circ}$ al $100 \%$ por dos horas. 6,23

5. Se retiró la cubierta de cera de la corona clínica y se secaron en un paño seco por 45 minutos para colocarse en tubos de ensayo que contenían salicilato de metilo, que cubrió el doble del volumen de los órganos dentarios 6,23 .

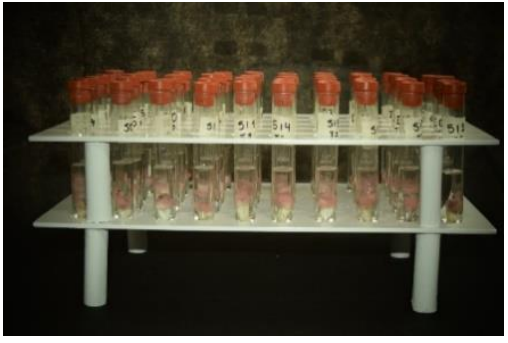

Fig. 7. Fotografía de las piezas dentales del estudio sumergidas en el Ácido Nítrico al $5 \%$.

Fuente. Propia.

Los dientes permanecieron en esta solución para que no pierdan sus propiedades de transparentación. 6, 23 (Fig. 8.)

\section{RESULTADOS}

Los resultados obtenidos de las 50 piezas dentales estudiadas (primeros premolares superiores) pudimos observar que según la clasificación de Vertucci de los 8 tipos solo logramos describir 5 tipos que fueron del Tipo 1; Tipo 2; Tipo 4; Tipo 5; Tipo 8; además de una pieza dental que presenta una morfología peculiar las misma que fue descrita como una variación de la clasificación de Vertucci por Gulabivala; esta morfología fue observada gracias al uso de la tomografía ya que por medio de la radiografía periapical esta pieza se observa como un solo conducto estrecho. Dicha pieza presentaba dos conductos separados que partían

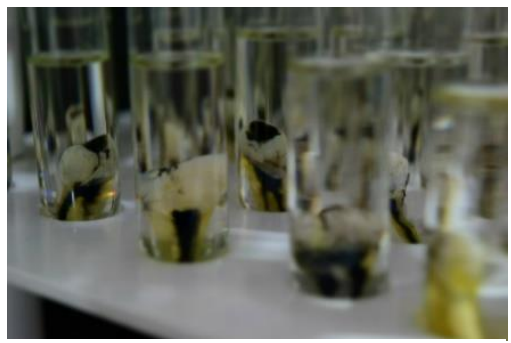

Fig. 8. Fotografía de los dientes estudiados durante el proceso final de transparentación.

Fuente. Propia. de la cámara pulpar que, al inicio del tercio medio se unen formando un conducto para inmediatamente volverse a separar en dos conductos nuevamente y finalmente al inicio del tercio apical se vuelven a unir formando un conducto y terminando en un único ápice radicular.

En la Tabla 1. podemos observar la variación en los resultados ya que del Tipo 1 obtenemos un total de 33 piezas con esta morfología siendo 12 en el grupo T1 y 21 en el grupo T2 en el Tipo 2 fueron un total de 3 piezas de las cuales fueron 2 del grupo T1 y una pieza del grupo T2, en el Tipo 4 se encontraron una total de 7 piezas con esta morfología de las cuales 5 fueron del grupo T1 y 2 fueron del grupo T2, del Tipo 5 se encontraron 5 piezas de las cuales 3 fueron de grupo T1 y 2 del grupo T2; en el caso de las piezas del Tipo 8 tan solo se encontraron 2 que se encontraban en el grupo T1. Dando un total de 50 piezas clasificadas por medio de la clasificación de Vertucci las mismas que fueron descritas usando de la radiografía periapical.

Tabla 1. RADIOGRAFIA PERIAPICAL

\begin{tabular}{|c|c|c|c|c|c|}
\hline & $\underset{1}{\text { TIPO }}$ & $\begin{array}{l}\text { TIPO } \\
2\end{array}$ & $\begin{array}{l}\text { TIPO } \\
4\end{array}$ & $\begin{array}{l}\text { TIPO } \\
5\end{array}$ & $\begin{array}{l}\text { TIPO } \\
8\end{array}$ \\
\hline$T 1$ & 12 & 2 & 5 & 3 & 2 \\
\hline T2 & 21 & 1 & 2 & 2 & \\
\hline TOTAL & 33 & 3 & 7 & 5 & 2 \\
\hline
\end{tabular}

Tabla 2. TOMOGRAFIA

\begin{tabular}{llllll}
\hline & TIPO & TIPO & TIPO & TIPO & TIPO \\
& $\mathbf{1}$ & $\mathbf{2}$ & $\mathbf{4}$ & $\mathbf{5}$ & $\mathbf{8}$ \\
\hline 1 & 10 & 2 & 9 & 1 & 2 \\
$T 2$ & 14 & 8 & 2 & 1 & \\
TOTAL & 24 & 10 & 11 & 2 & 2 \\
\hline
\end{tabular}

En el caso de la tomografía podemos observar en la Tabla 2 que un total de 24 piezas presentaron una morfología del Tipo 1 siendo 10 del grupo T1 y 14 del grupo T2; del Tipo 2 se encontraron 8 piezas siendo 2 del grupo T1 y 8 del grupo T2; del Tipo 4 se encontraron 11 piezas de las cuales 9 son del grupo T1 y 2 del grupo T2, del tipo 5 se encontraron 2 piezas, una en el grupo T1 y una en el grupo T2; en el caso de las piezas 
del Tipo 8 tan solo se encontraron 2 que se encontraban en el grupo T1. Dando un total de 49 piezas catalogadas por medio de la clasificación de Vertucci las mismas que fueron descritas usando de la tomografía, la pieza faltante es la pieza etiquetada como SD 3 del grupo T2 la misma que presento una morfología peculiar la cual pudimos encontrar en la clasificación de modificaciones de Gulabivala, la cual se basa en las modificaciones encontradas de la clasificación de Vertucci siendo esta pieza Tipo (2-1-2-1). (Fig. 9.)

Además debemos mencionar que se tomó en cuenta la presencia de ápices que se abren antes de la longitud total de la pieza en otras palabras que no se abren en el vértice

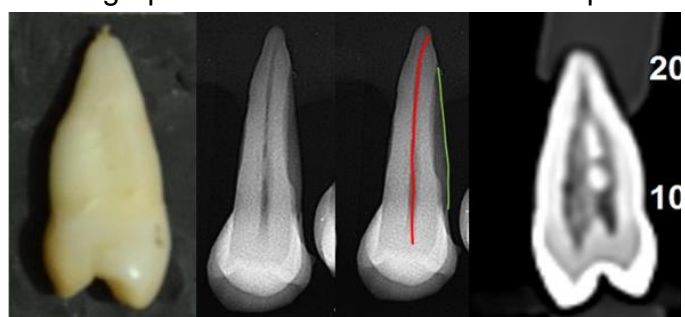

Fig. 9. Comparación entre el uso de la radiografía peripical y la CBCT para el estudio de la morfología interna. Fuente. Propia de la raíz tanto en la revisión por medio de las radiografías periapicales como con el uso de la tomografía, lo cual dio como resultado que:

\begin{tabular}{|c|c|c|}
\hline & MESIAL & $\begin{array}{ccc}\text { PORCENTAJE } & \text { EN } \\
\text { DISTAL TOTAL RELACIÓN A } & \text { LA } \\
\text { MUESTRA } & \\
\end{array}$ \\
\hline & ID 3 & SD 5 \\
\hline & SI 1 & ID 4 \\
\hline & SD 2 & SI 1 \\
\hline & SD 3 & SI 5 \\
\hline & SD 6 & \\
\hline TOTAL & 5 & $4 \quad 9$ \\
\hline $\begin{array}{l}\text { Fuente: } \\
\text { muestra } \\
\text { Premola } \\
\text { Autor: } D\end{array}$ & $\begin{array}{l}\text { Datos ob } \\
\text { total de } \\
\text { es Superio } \\
\text { iego Cobos }\end{array}$ & $\begin{array}{l}\text { enidos del estudio radiográfico de una } \\
0 \text { piezas dentales extraídas (Primeros } \\
\text { es). }\end{array}$ \\
\hline
\end{tabular}

Por medio de la radiografía periapical se observó en la Tabla 3 un total de 9 piezas dentales que presentaban la apertura del foramen apical antes del vértice de la raíz lo que nos representa un $18 \%$ de la muestra de las cuales 5 fueron hacia mesial y 4 hacia distal

\begin{tabular}{|c|c|c|c|c|}
\hline & MESIAL & DISTAL & TOTAL & $\begin{array}{l}\text { PORCENTAJE EN } \\
\text { RELACIÓN A LA } \\
\text { MUESTRA }\end{array}$ \\
\hline & ID 1 CON.P. (T1) & ID 2 (T1) & & \\
\hline & ID $3(\mathrm{~T} 1)$ & ID 4 CON.V (T1) & & \\
\hline & ID 4 CON.P. (T1) & ID 5 CON.P (T1) & & \\
\hline & II 3 (T1) & ID $6(\mathrm{~T} 1)$ & & \\
\hline & SD 3 CON.V (T1) & II 4 (T1) & & \\
\hline & SD 3 CON.P (T1) & II 6 (TI) & & \\
\hline & SI 1 (T1) & SD 5 (T1) & & \\
\hline & SI 5 (T1) & ID 1 (T2) & & \\
\hline & ID 3 CON.V (T2) & ID 3 CON.P (T2) & & \\
\hline & $\mathrm{SC}(\mathrm{T} 2)$ & ID 4 (T2) & & \\
\hline & $\mathrm{SD} 3(\mathrm{~T} 2)$ & ID 6 (T2) & & \\
\hline & $\mathrm{SD} 6(\mathrm{~T} 2)$ & SD 5 CON.V (T2) & & \\
\hline & $\mathrm{SI} 2$ (T2) & SD 5 CON.P (T2) & & \\
\hline & $\mathrm{SD} 2(\mathrm{~T} 2)$ & $\mathrm{SI} 5$ (T2) & & \\
\hline TOTAL & 14 & 14 & 28 & $56 \%$ \\
\hline \multicolumn{5}{|c|}{$\begin{array}{l}\text { Fuente: Datos obtenidos del estudio por medio de Tomografía Computarizada de Haz } \\
\text { Cónico de una muestra total de } 50 \text { piezas dentales extraídas (Primeros Premolares } \\
\text { Superiores). } \\
\text { Autor: Diego Cobos } P \text {. }\end{array}$} \\
\hline
\end{tabular}


Por otro lado en la Tabla 4 por medio de los cortes tomográficos pudimos observar que en un total de 28 piezas estudiadas presentaron el foramen apical antes del vértice de la raíz siendo un $56 \%$ de la muestra de la misma manera tomando en cuenta que 14 fueron hacia mesial y 14 hacia distal. (Fig. 10.)

Fig. 10. Comparación entre el uso de la radiografía peripical y la CBCT para observar el foramen apical. Fuente. Propia.

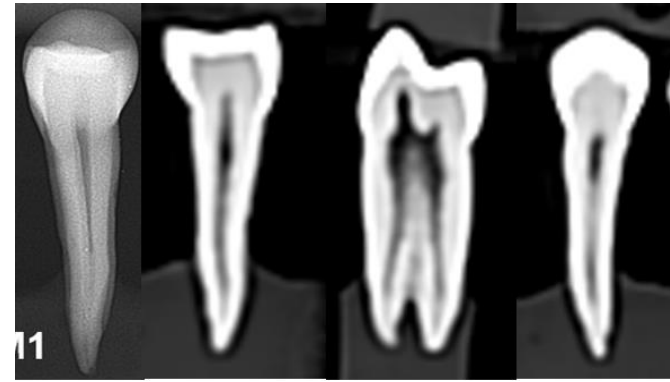

Primer Premolar Superior Tipo 1
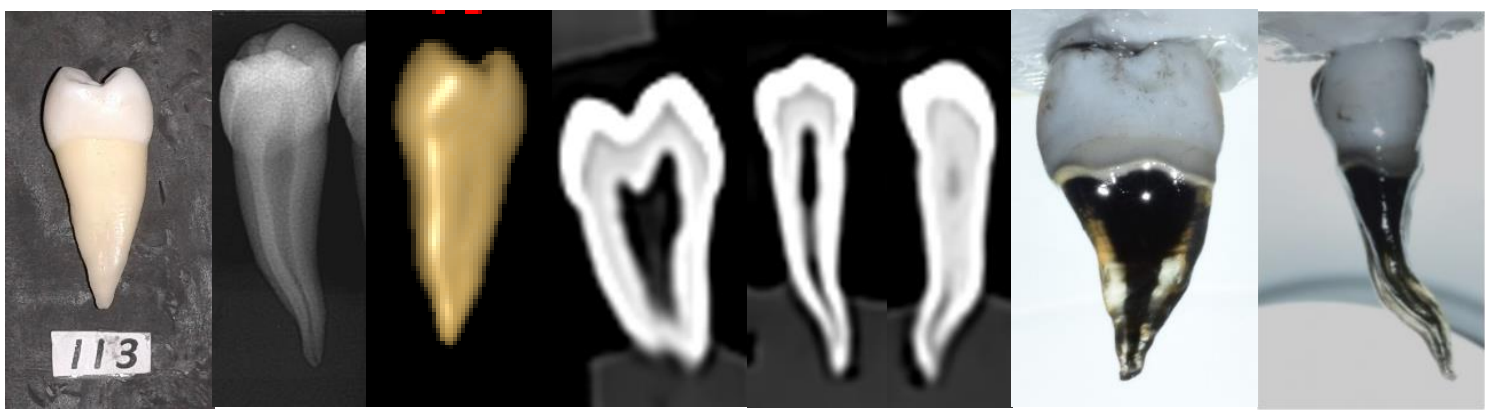

Figura 11. Pieza Tipo 1 según la clasificación de Vertucci, donde podemos observar un solo conducto con un trayecto complicado de su anatomía radicular.

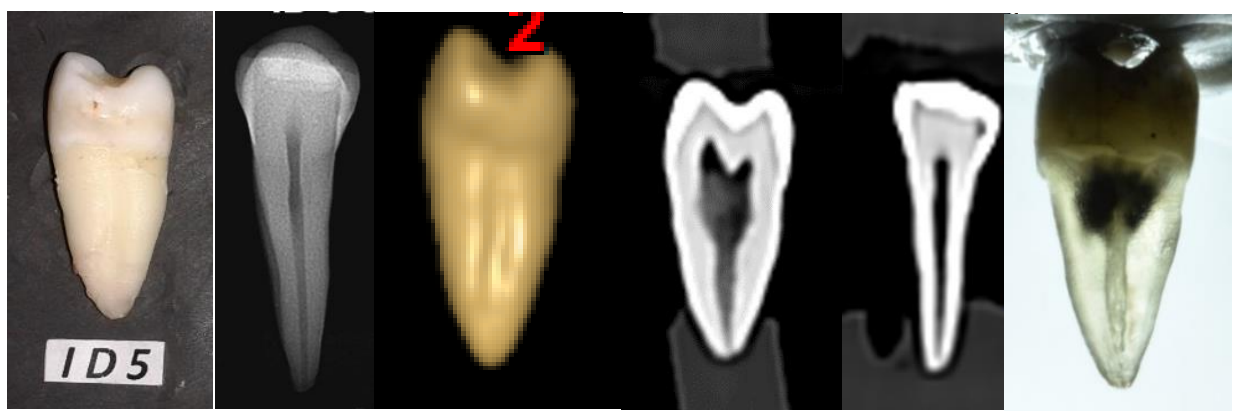

Figura 12. Pieza Tipo 1 según la clasificación de Vertucci donde podemos observar un solo conducto con un trayecto recto siendo algo inusual.

Primer Premolar Superior Tipo 2
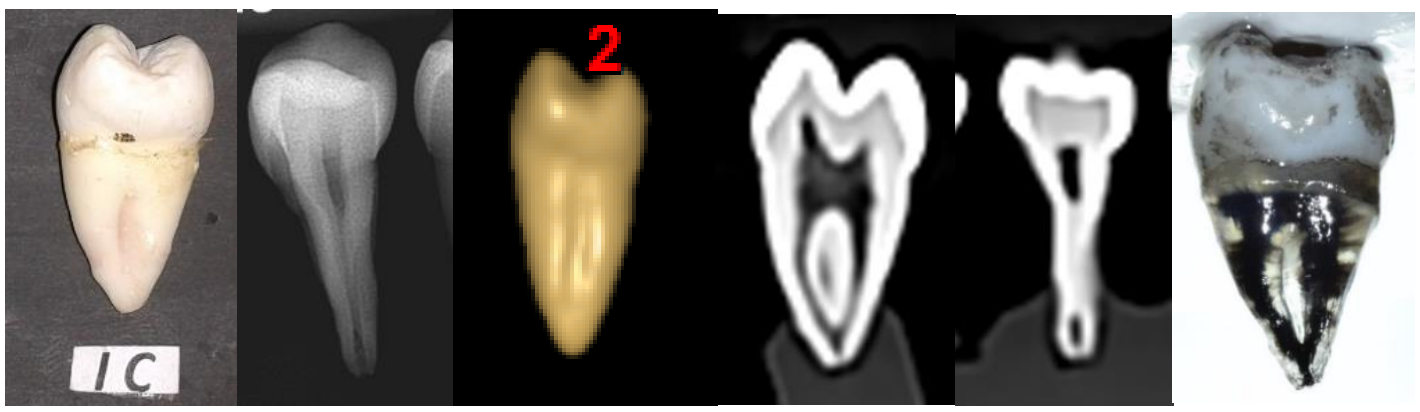

Figura 13. Pieza Tipo 2 según la clasificación de Vertucci donde podemos observar la super posición de imágenes en la radioigrafia periapical; tomografícamente obseramos claramente como parte dos conductos desde la cámara pulpar para luego unirse en el tercio apicla para teriinar en un solo conducto. 

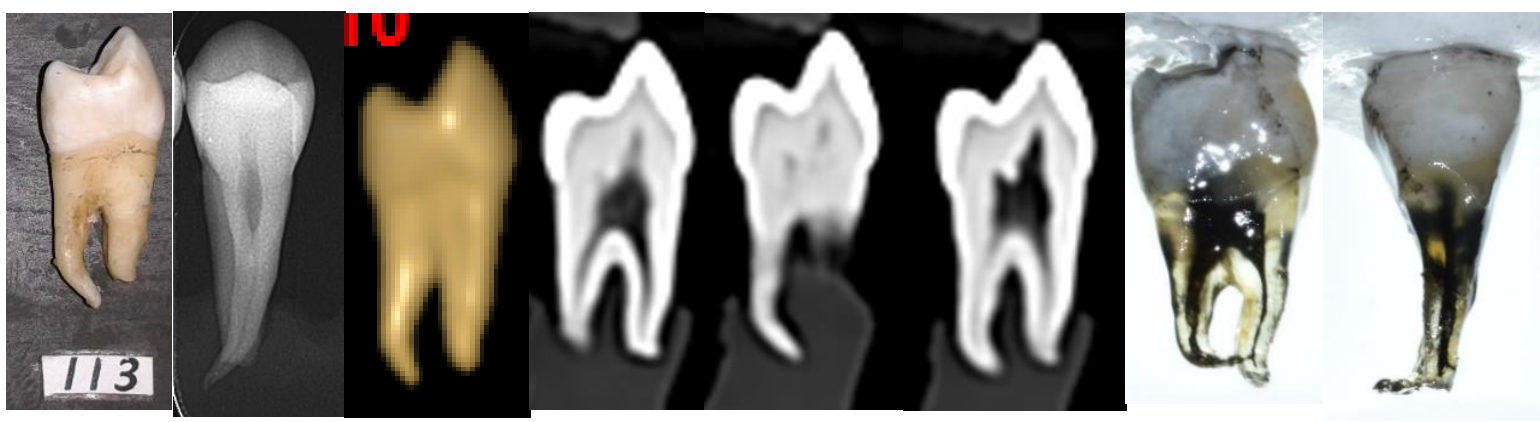

Figura 14. Pieza Tipo 4 según la clasificación de Vertucci.

Donde observamos un caso particular ya que la pieza presenta una morfología peculiar a nivel radicular, sus conductos radiculares son extremadamente delgados lo cual dificulto el estudio tomográfico ya que el conducto palatino no se pudo observar con claridad sin embargo en la radiografía periapical a pesar de la superposición de imágenes podemos observar prácticamente la forma del conducto palatino pero no podemos observar la forma del conducto vestibular.

Premolar Superior Tipo 5

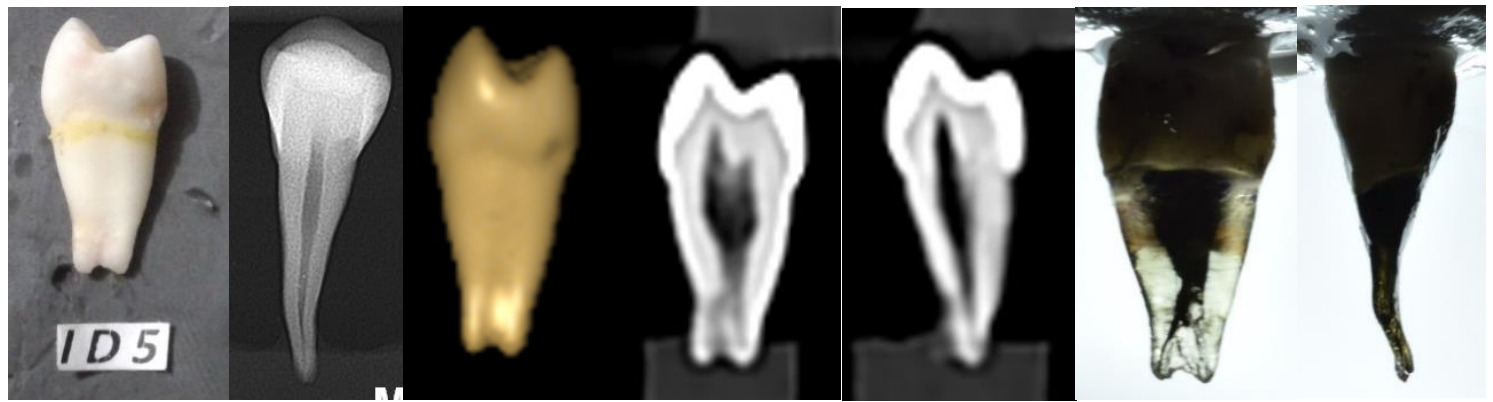

Figura 15. Pieza Tipo 5 según la clasificación de Vertucci

Donde podemos observar el trayecto complicado de su anatomía interna ya que esta pieza presenta un conducto radicular que al final de su tercio medio se divide en dos conductos.

Premolar Superior Tipo 8
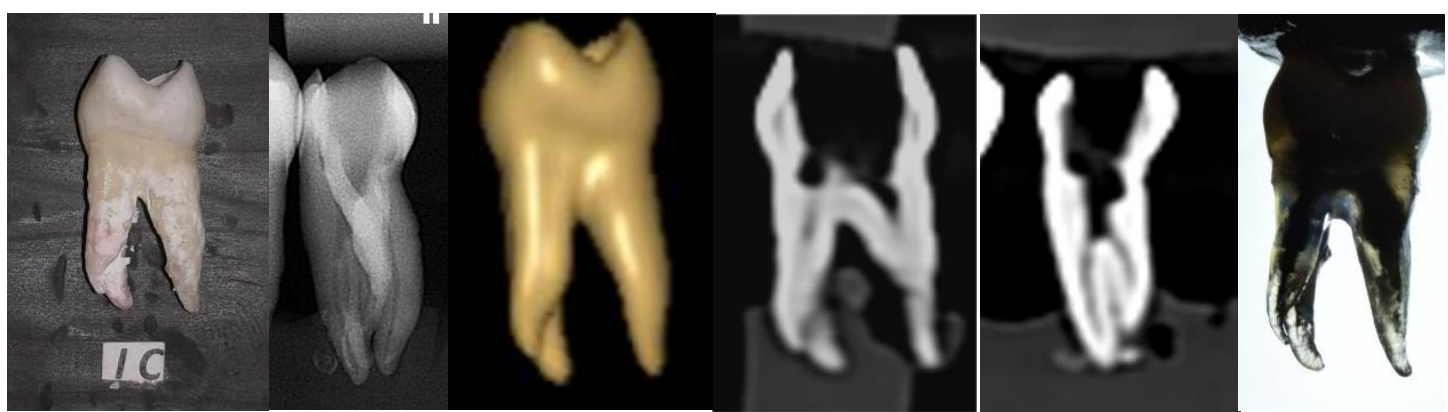

Figura 16. Pieza Tipo 8 según la clasificación de Vertucci

Donde se observa la presencia de tres raíces dentales lo cual complica el estudio radiográfico incluso tomográficamente es necesario realizar varios cortes para obtener una imagen clara de cada conducto.

Primer Premolar Superior Tipo 2-1-2-1 (Gulabivala)

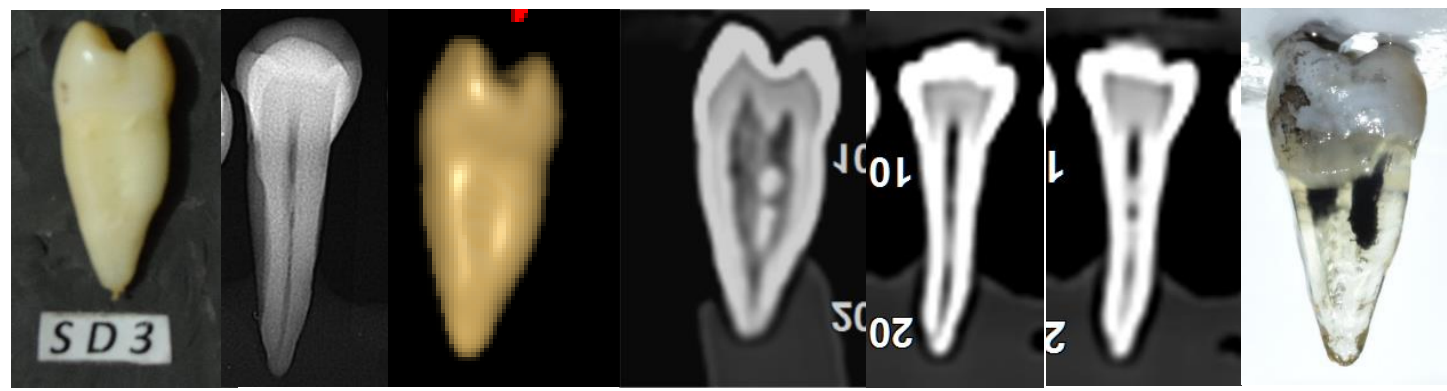


Figura 17. Pieza Tipo 2-1-2-1 según la clasificación de Gulabivala

En este caso podemos observar una morfología inusual ya que radiográficamente no se pudo detectar la morfología que realmente presentaba la pieza, ya que tomográficamente pudimos observar que inicialmente parte dos conductos separados de la cámara pulpar para luego unirse en uno en su tercio medio e inmediatamente volverse a separar en dos conductos para finalmente en el tercio apical unirse y terminar en un solo conducto.

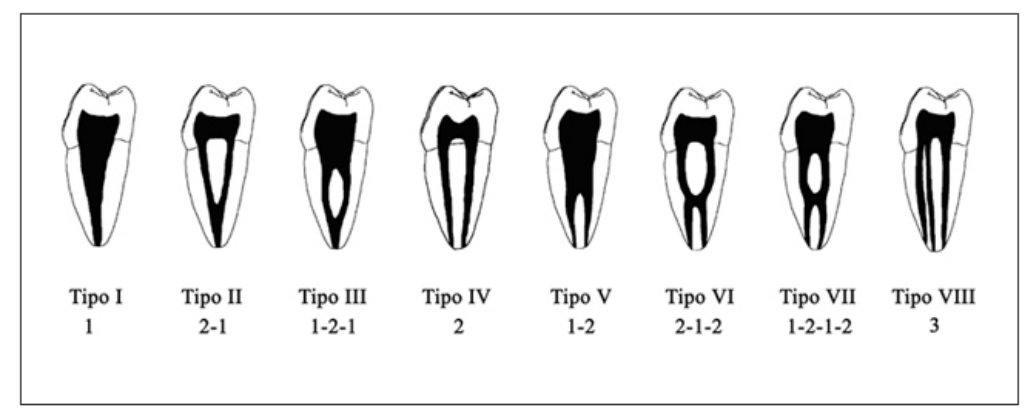

Figura 18. Tipos de conductos que podemos encontrar en primer premolar superior

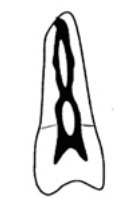

Type (2-1-2-1)

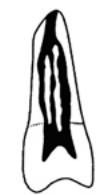

Type (3-1)

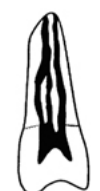

Type (3-2)

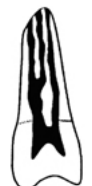

Type (2-3)

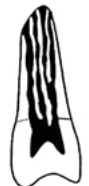

Type (3-4)

Figura 19. Clasificación adicional de Gulabivala 2002

\section{DISCUSIÓN}

Una de las técnicas más utilizadas para el estudio de la morfología interna de piezas dentales es por medio de la diafanización con relleno interno de tinta siendo Morel en 1914 uno de los primeros en utilizar esta técnica; incluso Vertucci realizó su estudio de la morfología interna de piezas dentales en 1979 dando una de las mejores clasificaciones de dichas estructuras, convirtiéndose en el punto de partida para estudios posteriores sin embargo, por la variante morfología interna de las piezas estudiadas esta técnica demostró muchas falencias.

En el aspecto clínico es importante el estudio minucioso de la radiografía de diagnóstico, especialmente para determinar el número de conductos principales, ya que Yoshica y cols. estudiaron la fiabilidad radiográfica para observar dos conductos en premolares inferiores y al compararla con la diafanización, tras la extracción comprobaron la correspondencia diagnóstica. Según lo observado en los resultados según el caso será necesario el uso de más de una radiografía para poder observar la forma y el trayecto de los conductos radiculares.

Lozano y cols. Compararon la efectividad de dos sistemas digitales con la radiografía convencional, tras la observación radiográfica. Concluyeron que las observaciones encontradas con la radiografía convencional eran más precisas que los sistemas digitalizados; durante el estudio realizado se pudo observar una gran calidad en las imágenes de la radiografía digital lo cual nos permitió en muchos de los casos dar un diagnóstico acertado.

Según lo mencionado por la doctora Lenguas Silva, Ana Leticia y col. en su publicación del 2 de agosto del 2010 menciona que la CBCT puede considerarse una técnica de gran potencial en odontología, pero aún está lejos de reemplazar el uso de la radiografía convencional, puesto que son muchos los factores que limitan su utilización, incluyendo, el elevado costo del equipo y el de los estudios de la figura tomográfica, la formación sofisticada del operador, el mayor tiempo requerido para la manipulación e interpretación. 
Aunque el uso de la tomografía computariza de haz cónico hoy por hoy es la técnica más acertada para realizar un diagnóstico y analizar la morfología del conducto radicular previo el tratamiento a realizar, probablemente aún no tenemos un medio $100 \%$ exacto para describir la morfología interna de las piezas dentales en pacientes que necesitan un tratamiento endodóntico; puesto que como se pudo observar en el estudio realizado que en un caso en el que el conducto radicular es muy fino, no se lo pudo observar y el mismo se presentaba como un conducto calcificado, pero en el resto del estudio se pudo ver una mayor exactitud en los detalles mostrando formas y estructuras que en la radiografía periapical y la diafanización no se pudo observar ya sea por la superposición de las estructuras en la radiografía o por problemas en el proceso de diafanización.

\section{CONCLUSIONES}

Se pudo observar durante el estudio una gran diversidad en la forma de las raíces ya que de la muestra total de las 50 piezas dentales estudiadas solo una presentó una raíz recta el resto de la muestra presentaron curvaturas y dilaceraciones y en cuanto al número de raíces estas variaron entre 1 a 3 raíces de las cuales las más comunes fueron la presencia de una raíz.

Al tener en frente una figura tomográfica que nos puede mostrar el diente en sus tres dimensiones como la que nos brida la CBCT nos ayuda de gran manera a conocer la trayectoria y forma de los conductos radiculares; encontrándose los mismo en su totalidad en la parte central de la corona de la pieza dental en el caso de dos conductos estos se encontraron en relación a la vertiente interna de las cúspides palatina y vestibular en los dos casos en los que se presentaron tres conductos los dos vestibulares se parten de un mismo conducto hasta el final del tercio cervical de la raíz.

Por medio de este estudio se pudo observar de manera clara la gran variedad en la morfología interna que puede presentar una pieza dental motivo por el cual nos basamos en la clasificación de Vertucci para realizar el estudio, con variaciones estandarizadas encontrando 5 de los 8 tipos descritos. Dichas variaciones encontradas fueron tipo 1, tipo2, tipo 4, tipo 5 y tipo 8; más una pieza que entra dentro de la clasificación de Gulabivala denominada tipo 2-1-2-1.

En el caso de las radiografías periapicales nos dejó como resultado que en varias piezas por la superposición de su propia morfología, ya sea por el número o forma de las raíces o conductos dentarios en muchos casos no se pudo apreciar con claridad la forma del conducto, la presencia de más de un conducto e incluso se volvió un tanto complicado observar la forma de la cámara pulpar.

Pese a las limitantes mencionadas se pudo realizar el estudio gracias a las diversas formas de interpretación de las radiografías periapicales y la gran variedad de cortes que se pueden realizar en las piezas dentales por medio de la tomografía pudiendo efectuar múltiples cortes para determinar la morfología interna de manera exacta. Por lo tanto podemos decir que para un estudio

de la morfología interna como el que acabamos de presentar la técnica más adecuada por exactitud en la interpretación y medición es por mucho la tomografía computarizada de haz cónico ya sea para realizarlo en piezas extraídas (In vitro) como en piezas en boca (In vivo); sin lugar a dudas el uso de la tomografía nos brinda una visión más detallada de la morfología interna en comparación con el uso de la radiografía periapical; siempre y cuanto tomemos en cuenta que ya sea usando radiografías o tomografía estos son solo un método complementario en el diagnóstico.

Agradecimiento al Dr. Juan Guillermo Hermida del Centro Radiológico Dental-Maxilofacial por su colaboración con la toma de radiografías digitales y tomografías para este estudio.

\section{REFERENCIAS BIBLIOGRÁFICAS}

1. Villaverde A., Garrido P., Vera C, Rodríguez N. Cone Beam Computed Tomography en endodoncia. DENTAL PRACTICE REPORT. Julio-Agosto 2012. Págs.: 37-40. Mississippi.

2. Ronda N. Aplicaciones de la TAC en endodoncia. Electronic Journal Of Endodontics Rosario. Volumen 2. Agosto 2012. Págs. 635-662. Rosario.

3. SlideShare[Internet]. México. Endoperiodoncista. 10 de noviembre de 2012. Propuesta de una metodologia de diafanizacion en endodoncia. universidad nacional autónoma de méxico. Disponible en: http://es.slideshare.net/urielst/diafanizacion-dental15116513 
4. Leonardo MR. Endodoncia - Tratamiento De Conductos Radiculares Tomo 1. Volumen 1. Brasil: Editorial Artes Medicas. 2005. Págs. 485-494.

5. Concha I. Diafanización. Unidad de Anatomía Veterinaria. Universidad Santo Tomas, Chile. Santiago 2006.

6. Soares IJ, Goldberg F. Endodoncia: Técnicas y fundamentos. Ed. En español. Argentina: Panamericana;

7. Manual de Radiología Odontológica. Colombia de Salud. Revisión 02. Marzo 2013. Págs. 02-17. Colombia.

8. Leonardo MR. Endodoncia - Tratamiento De Conductos Radiculares Tomo 1. Volumen 1. Brasil: Editorial Artes Medicas. 2005. Págs. 481-483

9. Moenne M., Anatomía Premolares, Postgrado Endodoncia 2013, Universidad de Valparaíso. 6 de mayo 2013. Págs.: 1-32. Valparaíso.

10. Kenneth M. Hargrevas, Stephen Cohen. Vías de la pulpa. Décima Edición. Barcelona España: Elseiver Mosby. 2011. Págs. 138-141.

11. R. Nageswar R. Endodoncia Avanzada. Volumen. Edición 2011. Lugar de Publicación. Editorial AMOLCA. 2011. Págs.

12. Polanco R. Patenticidad Apical. Patenticidad Lateral. Conductos Laterales. Deltas apicales. Conceptos Actuales. Universidad Central de Venezuela. Venezuela 2002-2004. Disponible en: http://www.carlosboveda.com/Odontologosfolder/odontoinvitadoold/odontoinvitado 39.htm

13. Carlos Canalda Sahil, Esteban Brau Aguadé. Endodoncia Técnicas Clínicas y Bases Científicas. Segunda Edición. España: Editorial Elsevier Masson. 2006. Págs. 13-14.

14. Greco Y, García J.A., Lozano V., Manzanares M.C. Morfología de los conductos radiculares de premolares superiores e inferiores. ENDODONCIA. Volumen 27. Número 1. Enero-Marzo 2009. Págs.: 13-18. Madrid.

15. Estévez R., de la Torre F., Aranguren J, Tejedor B., Cisneros R. Tomografía computarizada en endodoncia: usos e indicaciones. ENDODONCIA. Volumen 27. Número 2. Abril-Junio 2009. Págs.: 80-85.Madrid.

16. Lenguas A.L, Ortega R., Samara G., López M.A. Tomografía computarizada de haz cónico. Aplicaciones clínicas en odontología; comparación con otras técnicas. Científica dental (Cient Dent) 2010. Págs.: 147-159. U.C.M.

17. Kenneth M. Hargrevas, Stephen Cohen. Vías de la pulpa. Decima Edicion. Barcelona España: Elseiver Mosby. 2011. Págs. 20-22

18. 2003Hargreaves K., Cohen E., Berman L., Preparación de las Radiografías. Vías de la Pulpa. Décima Edición. Capítulo 5. Págs.: 98-109.

19. Montaño M. Tomografía Cone Beam 3d Su Aplicación En Odontología. Revista de Actualización Clínica. Volumen 38. 2013. Págs.: 1897-1901. Bolivia.

20. Versiani M., Pécora J., Sousa M., Antúnez M., Olguín C. Micro-Tomografía Computarizada en Endodoncia. Canal Abierto. № 27. Abril 2013 Págs.: 32-37. Chile.

21. Hargreaves K., Cohen E., Berman L., Morfología del diente y preparación de la cavidad de acceso. Vías de la Pulpa. Décima Edición. Capítulo 7. Págs.: 136-185. 